\title{
Effect of PPM1H on malignant phenotype of human pancreatic cancer cells
}

\author{
HAN ZHU ${ }^{1}$, HUA QIN ${ }^{1}$, DE-MIN LI ${ }^{1}$, JING LIU $^{2}$ and QIU ZHAO ${ }^{1}$ \\ ${ }^{1}$ Department of Gastroenterology, Tongji Hospital, Tongji Medical College, Huazhong University of Science and Technology; \\ ${ }^{2}$ Department of Gastroenterology, Zhongnan Hospital of Wuhan University, Wuhan, Hubei 430030, P.R. China
}

Received April 21, 2016; Accepted August 17, 2016

DOI: 10.3892/or.2016.5065

\begin{abstract}
The objective of this study was to investigate the effect of silencing gene protein phosphatase $1 \mathrm{H}(\mathrm{PPM} 1 \mathrm{H})$ on malignant phenotype of human pancreatic cancer cell line BxPC-3. In order to explore the function of PPM1H in pancreatic cancer cells, real-time PCR and western blotting were used to detect the expression of PPM1H in different pancreatic cancer cell lines. Human pancreatic cancer cell line BxPC-3 was treated with $10 \mathrm{ng} / \mathrm{ml}$ TGF- $\beta 1$ and $200 \mathrm{ng} / \mathrm{ml} \mathrm{BMP} 2$ for $72 \mathrm{~h}$, respectively, and the mRNA and protein expression levels of PPM1H and EMT-related markers (E-cadherin, vimentin) were detected by real-time PCR and western blotting, respectively. Using exogenous RNA interference technology to silence the PPM1H gene, the expression of PPM1H and EMT-related markers at mRNA and protein levels were detected by real-time PCR and western blotting. The cell migration and invasion were measured using Transwell assays. Finally, cell counting kit-8 (CCK-8) and flow cytometry were used to determine the effect of PPM1H on cell proliferation and apoptosis of BxPC-3 cells. The expression levels of $\mathrm{PPM} 1 \mathrm{H}$ in all of the examined pancreatic cancer cell lines (BxPC-3, MIA-PACA2, PANC-1, SW1990, PANC-03.27) were lower than that of normal pancreatic ductal epithelial cells (HPDE6-C7) at both mRNA and protein levels. Both TGF- $\beta 1$ and BMP2 treatment induced EMT and downregulation of PPM1H in BxPC-3 cells. By using RNA interference to transiently knock down PPM1H expression in BxPC-3 cells, we found that the expression of E-cadherin was downregulated while vimentin was upregulated. The data suggested that silencing PPM1H gene can induce EMT in BxPC-3 cells. In addition, Transwell migration assays showed that silencing PPM1H gene can promote the invasion and metastasis of
\end{abstract}

Correspondence to: Professor Qiu Zhao, Department of Gastroenterology, Tongji Hospital, Tongji Medical College, Huazhong University of Science and Technology, 1095 Jiefang Avenue, Wuhan, Hubei 430030, P.R. China

E-mail: zhaoqiu@medmail.com.cn

Key words: pancreatic cancer, PPM1H, epithelial-mesenchymal transition, migration, proliferation, apoptosis
BxPC-3 cells. Cell proliferation and apotosis detection demonstrated that silencing PPM1H gene can promote the proliferation and inhibit apoptosis of BxPC-3 cells. In conclusion, PPM1H is aberrantly expressed in human pancreatic cancer cell lines and can be downregulated when EMT is induced by cytokine stimulation. Silencing PPM1H gene can induce EMT in BxPC-3 cells, and promote the invasion and metastasis of BxPC-3 cells. Moreover, silencing PPM1H gene can promote the proliferation and inhibit apoptosis of BxPC-3 cells. PPM1H may be a new tumor-suppressor factor for pancreatic cancer and provides new insight into molecular targets for gene therapy of pancreatic cancer.

\section{Introduction}

Pancreatic cancer (PC) is one of the most common malignant tumors and remains a treatment-refractory cancer due to its early formation of metastases, poor prognostic and high mortality $(1,2)$. The incidence and mortality of PC are increasing world wide. Currently, the most common treatments for PC patients are surgical resection followed by adjuvant chemotherapy and radiotherapy. Unfortunately, $>80 \%$ of PC patients already have local invasion or distant metastasis when first diagnosed, and thus have lost the opportunity of surgical therapy. The overall 5-year survival rate of these patients is $<5 \%$ (3-5). Even for those patients whose pancreatic cancer can be surgically resected, followed by adjuvant chemotherapy and radiotherapy, the overall 5-year survival rate is $<25 \%(6,7)$. The high metastatic potential, strong growth and chemotherapy resistance are the main causes of high mortality of pancreatic cancer $(8,9)$. However, the multiple metastasis mechanism of PC remains unclear. Therefore, understanding the key factors involved in these processes is urgently needed to explore new therapeutic targets of PC.

Accumulating evidence demonstrates that epithelial-mesenchymal transition (EMT) could promote cell proliferation, cell motility and aggression, as well as anti-apoptotic ability and chemotherapy resistance (10-14). The key step of EMT is that the expression of epithelial phenotype E-cadherin is downregulated, which plays an important role in the maintenance of cell interactions and epithelial cell polarity. Moreover, the expression of mesenchymal phenotype such as vimentin, $\mathrm{N}$-cadherin, $\alpha$-SMA, fibronectin are upregulated (15-17). The deletion of E-cadherin in pancreatic cancer is associated with 
the increase of tumor size, distant metastasis and pathological staging (18). Upregulation of mesenchymal phenotype could decrease the sensitivity of PC cells to chemotherapeutic drugs, and increase the resistance to chemotherapy $(19,20)$.

Transforming growth factor- $\beta 1$ (TGF- $\beta 1$ ) and bone morphogenetic proteins 2 (BMP2) are both members of transforming growth factor- $\beta$ superfamily, which are involved in cell proliferation, differentiation, apoptosis, metastasis and angiogenesis (21-25). Dysregulation of their pathway contributes to a variety of pathologies, including cancer, fibrosis and inflammation. In the early stage of tumor, TGF- $\beta 1$ exhibits tumor suppressive effects by inhibiting cell cycle progression and promoting apoptosis. However, in the late stage TGF- $\beta 1$ exerts tumor promoting effects by increasing tumor invasiveness and metastasis. BMP2 also has a similar dual effect. High expression of TGF- $\beta 1$ and BMP2 in tumor tissue or blood of patients may be correlated with disease progression and poor prognosis. A huge number of studies indicated that both TGF- $\beta 1$ and BMP2 may be involved in the process of EMT in PC cells through Smad signaling pathway or non-Smad signaling pathway so as to increase the ability of invasion and metastasis (26-30), and the latter may play a more important role. However, the concrete mechanism has not been elucidated yet.

Protein phosphatase $1 \mathrm{H}(\mathrm{PPM} 1 \mathrm{H})$, a member of the PP2C family of serine/threonine protein phosphatases, which was originally identified as a negative regulator of neurite outgrowth, was comprehensively expressed in healthy human tissues (GeneCards: http://www.genecards.org/cgi-bin/ carddisp. pl?gene=PPM1H\&search=PPM1H). PPM1H was reported to control cell proliferation and differentiation (31-34). Recently, it has been indicated to participate in the process of cancer development (31-33). However, the role of PPM1H in cancer remains controversial. Previously, PPM1H was found to be downregulated in glioblastoma and renal cell carcinoma compared to normal brain and kidney but upregulated in colon adenocarcinoma and prostate adenocarcinoma compared to normal colon and prostate. It was also demonstrated that low PPM1H expression in breast cancer trend toward trastuzumab resistance and worse clinical outcome. These studies suggested that the role of PPM1H may differ depending on the cancer type and its exact mechanism of action in cancer remains largely unknown. Until now, no attempt was made to examine the role of PPM1H in pancreatic cancer.

In this study, we examined the expression of PPM1H in human PC cell lines. In addition, we explored the role of PPM1H in inducing EMT as well as promoting human PC cell migration. Furthermore, we determined the effect of PPM1H depletion on the proliferation and apoptosis of human PC cells.

\section{Materials and methods}

Cell lines and cell culture. The human pancreatic cancer cell lines PANC-1, BxPC-3, PANC-03.27, SW1990, MIA-PACA2 and the normal human pancreatic epithelial cell line HPDE6-C7 were used in this study. The cell lines PANC-1, BxPC-3 and HPDE6-C7 were purchased from the cell bank of the Chinese Academy of Sciences (Shanghai, China), and the other cells were obtained from the American Type Culture
Collection (ATCC). The cell lines BxPC-3, PANC-03.27, MIA-PACA2 and HPDE6-C7 were cultured in RPMI-1640 medium (Gibco, Rockville, MD, USA) containing 10\% fetal bovine serum (Gibco) and the cell lines PANC-1 and SW1990 were cultured in DMEM medium (Gibco) containing 10\% fetal bovine serum (Gibco). All of the cells were grown at $37^{\circ} \mathrm{C}$ in a humidified atmosphere containing $95 \% \mathrm{O}_{2}$ and $5 \%$ $\mathrm{CO}_{2}$. BxPC-3 cells were grown to approximately $60 \%$ confluency in RPMI-1640 $+10 \%$ FBS and were then serum-deprived overnight in RPMI-1640 medium. Cells were then treated with 10 ng/ml TGF- $\beta 1$ or 200 ng/ml BMP2 (Peprotech Inc., Rocky Hill, NJ, USA) for $72 \mathrm{~h}$. The morphology of cells was visualized with a phase contrast microscope (x200, Nikon, Japan) and imaged with digital photography.

siRNA transfection. siRNA targeting human $\mathrm{PPM} 1 \mathrm{H}$ (5'-CACGCUUCUUUACCGAGA-3' and 5'-UCUCGGUA AAGAAGCGUG-3' duplex) was synthesized by Ribobio Co. (Guang Zhou, China). A scrambled duplex siRNA was used as the negative control. BxPC-3 cells were plated at $2 \times 10^{5} /$ well in 6-well plates and incubated until they reached $50 \%$ confluency. Cells were transfected with PPM1H siRNA or the negative control siRNA at a final concentration of $50 \mathrm{nM}$ with Lipofectamine 2000 Transfection Reagent (Invitrogen, Carlsbad, CA, USA) according to the manufacturer's recommendations. After $6 \mathrm{~h}$ of transfection, the medium was replaced with RPMI-1640 medium containing $10 \%$ fetal bovine serum. Cells were then incubated for $72 \mathrm{~h}$ for RNA isolation and protein extraction.

RNA isolation and quantitative RT-PCR ( $q R T-P C R)$. The total RNA from BxPC-3 cells was extracted using the TRIzol reagent (Takara, Inc., Otsu, Japan) according to the manufacturer's instructions and was resuspended in nuclease-free water. Then, $500 \mathrm{ng}$ of total RNA was reverse-transcribed in a final volume of $10 \mu \mathrm{l}$ with PrimeScript ${ }^{\mathrm{TM}}$ II First-Strand cDNA Synthesis kit (Takara, Inc.). The reverse transcription reaction was processed at $37^{\circ} \mathrm{C}$ for $15 \mathrm{~min}, 85^{\circ} \mathrm{C}$ for $5 \mathrm{~S}$ and $4^{\circ} \mathrm{C}$ for 10 min. qRT-PCR was performed using the SYBR Green Master Mix (Takara, Inc.) on StepOne Real-time PCR systems (Applied Biosystems, Foster City, CA, USA) in triplicate, and non-template controls were run for each assay under the same conditions. The PCR reaction was carried out with an initial denaturation step of $95^{\circ} \mathrm{C}$ for $30 \mathrm{sec}$ followed by 40 cycles of $95^{\circ} \mathrm{C}$ for $5 \mathrm{sec}$ and $60^{\circ} \mathrm{C}$ for $30 \mathrm{sec}$. Primers used for real-time PCR were as follows: PPM1H (forward, 5'-GCATTCATGC AGCCTCACTTGC-3', reverse, 5'-GCCATCCTCTGTCC TTCAGCAC-3'); E-cadherin (forward, 5'-ACAGCCCCGC CTTATGATTCTC-3', reverse, 5'-AAGCGATTGCCCCAT TCGTT-3'); Vimentin (forward, 5'-CCTTGAACGCAAAG TGGAATC-3', reverse, 5'-GACATGCTGTTCCTGAATCT GAG-3'); $\beta$-actin (forward, 5'-GTTGCGTTACACCCTTT CTTG-3', reverse, 5'-GACTGCTGTCACCTTCACCGT-3'). The analysis of qPCR was carried out using the $2^{-\Delta \Delta C t}$ method. $\beta$-actin was taken as the internal control.

Western blotting. Proteins were extracted from cultured cells and then quantitated using Pierce BCA Protein Assay kit (Boster Biological Engineering Co., Ltd., Wuhan, China). Equal amounts of protein from different samples were separated by 


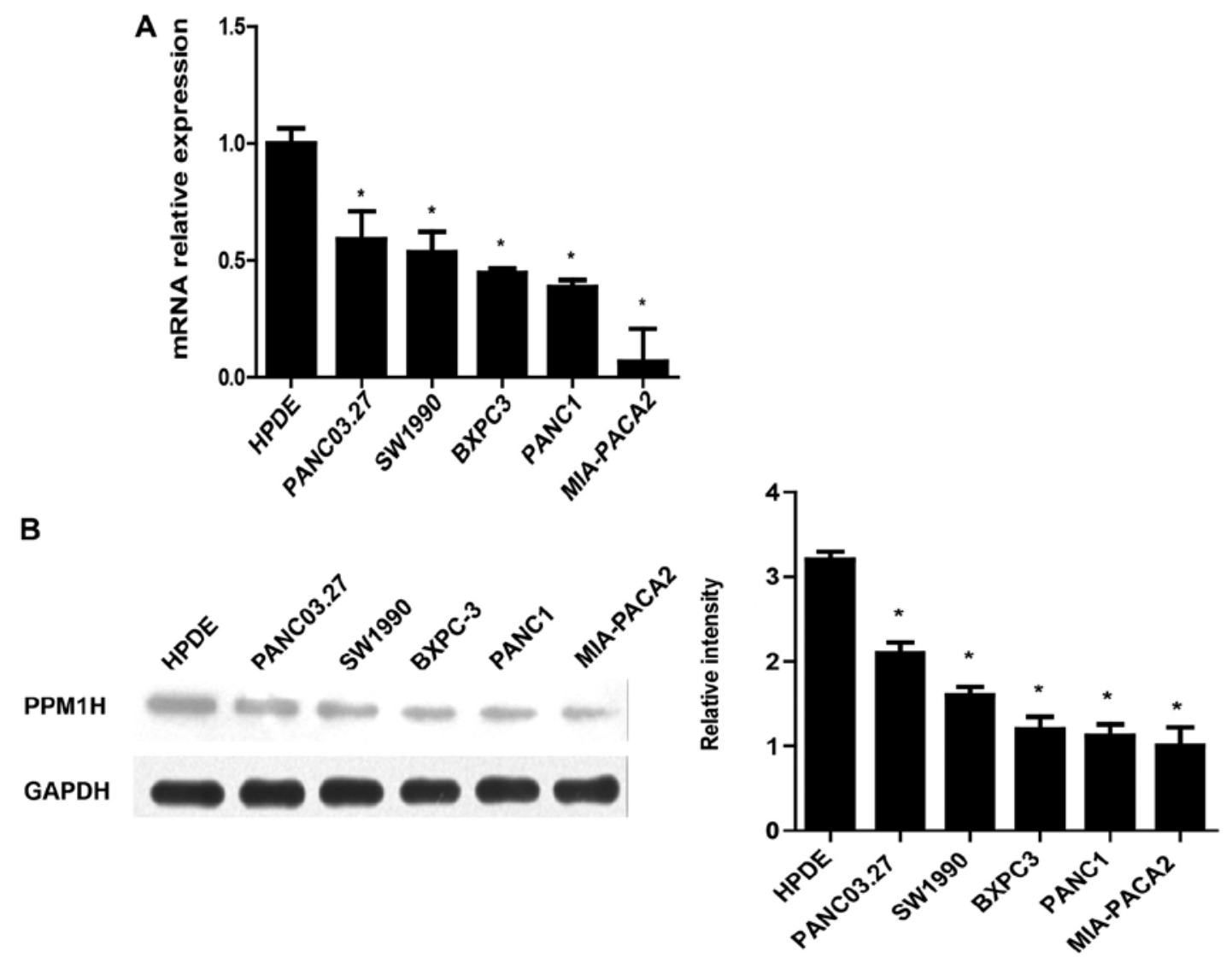

Figure 1. Expression of PPM1H in human normal pancreatic ductal epithelial cell line (HPDE6-C7) and different human pancreatic cancer cell lines (BxPC-3, MIA-PACA2, SW1990, PANC-1, PANC-03.27). (A) RT-PCR analysis of PPM1H in six cell lines. The relative mRNA levels with the use of control HPDE6-C7 were normalized to 1 . Values are given as means and standard deviations from more than three independent experiments when compared to control cells. ${ }^{*} \mathrm{P}<0.05$. (B) Western blot analysis of PPM1H in six cell lines. GAPDH is shown as a control.

$10 \%$ SDS/polyacrylamide gel in Tris-glycin buffer and transferred to PVDF membranes. The membranes were blocked for $1 \mathrm{~h}$ at room temperature in blocking buffer $(5 \%$ skim milk in 0.5 Tween-20-TBST), then probed with PPM1H antibody (Abgent, diluted 1:1000 in TBST), E-cadherin antibody (ProteinTech, diluted 1:800 in TBST), vimentin antibody (ProteinTech, diluted 1:5000 in TBST), akt antibody (CST, diluted 1:1000 in TBST) and p-akt antibody (CST, diluted 1:1000 in TBST), respectively, overnight at $4^{\circ} \mathrm{C}$ with GAPDH antibody (Promoter Biological Co., China, diluted 1:5000 in TBST) as control. Following washes with TBST, the membranes were incubated with HRP-conjugated goat antirabbit secondary antibody (Promoter Biological Co., diluted 1:5000 in TBST) for $1 \mathrm{~h}$ at room temperature. After extensive washing with TBST, the complex was detected by Super Signal West Pico Chemiluminescent Substrate (Thermo Fisher Scientific Inc., Waltham, MA, USA) according to the manufacturer's instructions. Blot was scanned and densitometric analysis was done by ImageJ software (National Institutes of Health, Bethesda, MD, USA).

Transwell cell invasion and migration assay. The cell invasion and migration was assessed using 24-well polycarbonate filters (membrane pore size $8 \mu \mathrm{m}$ ). Cells $\left(8 \times 10^{4}\right)$ were seeded in $100 \mu \mathrm{l}$ serum-free medium into the upper chamber and allowed to invade into the lower chamber, which was filled with $600 \mu$ l of RPMI-1640 medium containing 10\% FBS as a chemoattractant. The chamber for invasion assay was coated by Matrigel (BD Biosciences, Foster City, CA, USA). The Transwell plate was incubated at $37^{\circ} \mathrm{C}$ in a $5 \% \mathrm{CO}_{2}$ incubator for $24 \mathrm{~h}$, then the upper chamber was successively fixed with methanol and stained by $0.1 \%$ crystal violet for $25 \mathrm{~min}$. The upper chamber was then washed with PBS to remove excess stain and the unmigrated cells staying at the upper layer of the microporous membrane were gently scraped with a wet cotton swab. After drying, the stained migrated cells were counted with the phase contrast microscope. The average number of migrated cells per field was quantified under high power (x200).

Cell proliferation assay. Cell proliferation was analyzed using the Cell Count Kit-8 (CCK-8) assay. BxPC-3 cells were seeded in 96-well plates at a density of 10000 cells per well and transfected with PPM1H siRNA or the negative control siRNA when the cells reached $50 \%$ confluency, then incubated for 1, 2 or 3 days. At the indicated time point, CCK8 solution was added to each well and incubated for 1, 2, 3, $4 \mathrm{~h}$. The absorbance value (optical density) of each well was measured at $450 \mathrm{~nm}$. For each experimental condition, 6-wells were used. All experiments were performed thrice.

Flow cytometry. BxPC-3 cells were transfected with PPM1H siRNA or the negative control siRNA for $72 \mathrm{~h}$, then were harvested and washed with ice-cold PBS. The cells were 
A

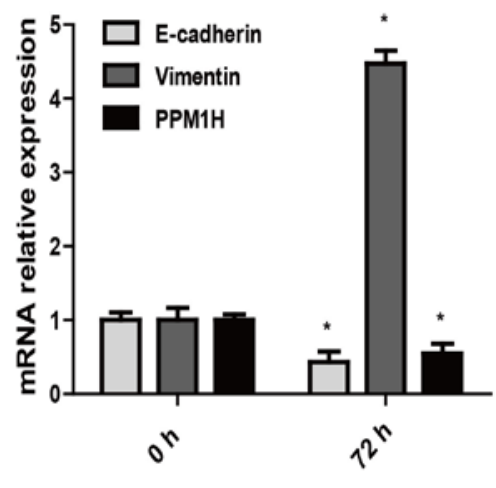

$\mathbf{O h}$

$72 \mathrm{~h}$
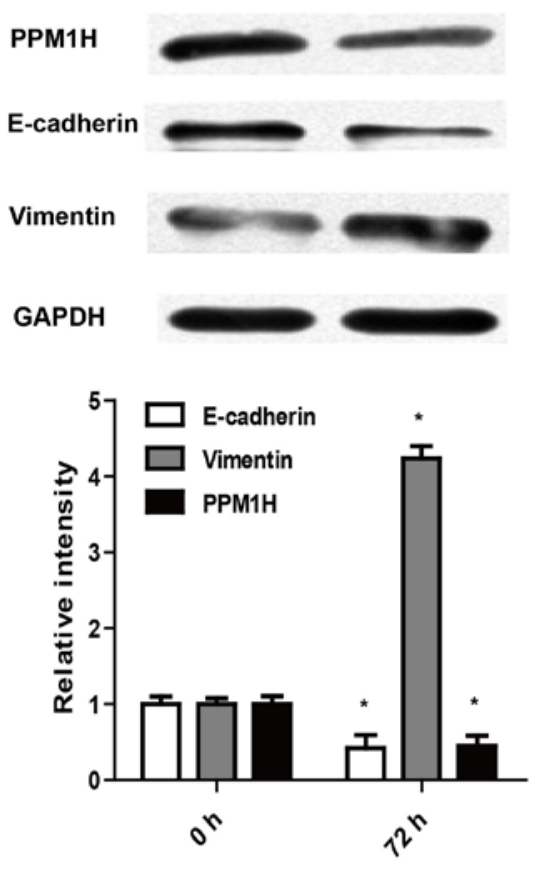
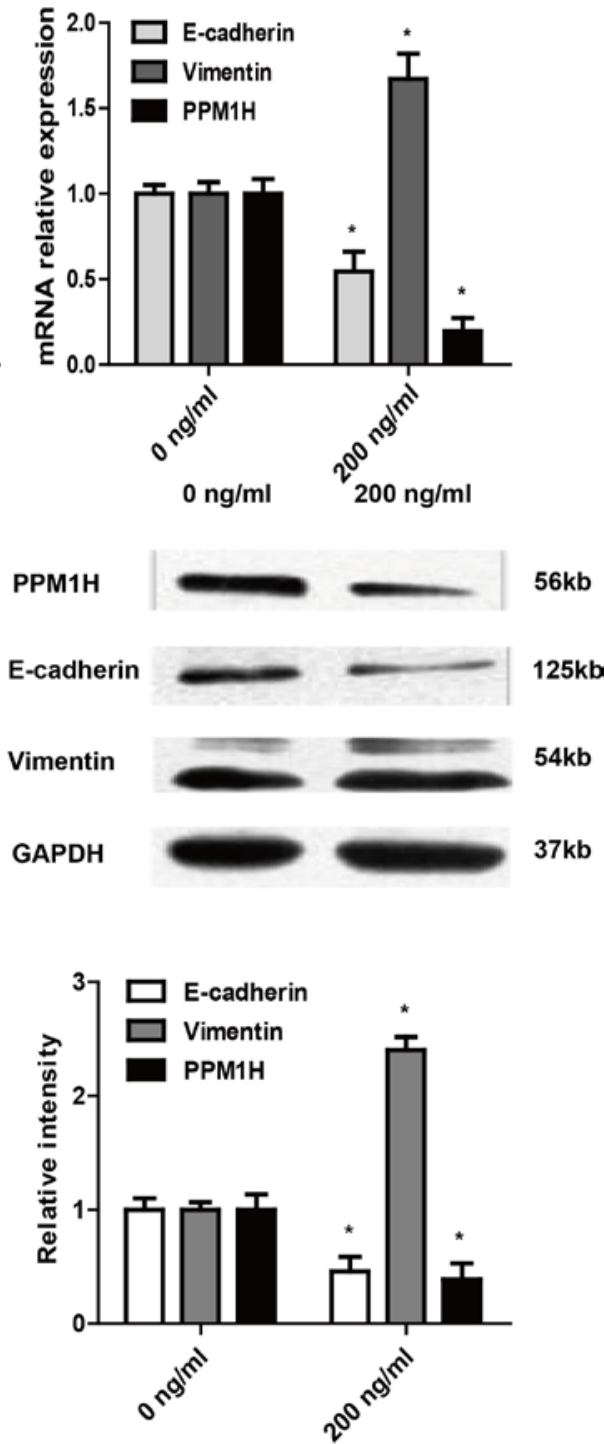

Figure 2. Effect of TGF- $\beta 1$ and BMP2 on the expression of EMT-related makers and PPM1H in BxPC-3 cell line. (A) Effect of $10 \mathrm{ng} / \mathrm{ml}$ TGF- $\beta 1$ on the expression of EMT related molecules and PPM1H in BxPC-3 cell line. (B) Effect of $200 \mathrm{ng} / \mathrm{ml} \mathrm{BMP2}$ on the expression of EMT related molecules and PPM1H in BxPC-3 cell line. Compared with control group. ${ }^{*} \mathrm{P}<0.05$.

trypsinized without EDTA and resuspended with binding buffer. Annexin V and PI staining were carried out using the Annexin V-FITC Apoptosis Detection kit (BDBiosciences, San Jose, CA, USA), according to the manufacturer's instructions. After a 15-min incubation in a dark at room temperature, the cells were immediately analyzed by FACScan flow cytometer.

Statistical analysis. Data were presented as mean \pm standard deviation (SD). Experiments were repeated at least three times. SPSS 17.0 software (IBM, Chicago, IL, USA) was used for data analysis. Group differences were analyzed by Student's $\mathrm{t}$-test or analysis of variance (ANOVA) according to the data type. $\mathrm{P}<0.05$ was considered statistically significant.

\section{Results}

Expression of PPMIH in pancreatic cancer cell lines. The expression of PPM1H in human pancreatic cancer cell lines
(BxPC-3, MIA-PACA2, SW1990, PANC-1, PANC-03.27) were analyzed by real-time PCR and western blotting. The real-time PCR results showed that PPM1H mRNA expression in PC cells were significantly lower than in normal pancreatic ductal epithelial cells (HPDE6-C7) (Fig. 1A). In addition, western blot data also showed lower expression of PPM1H in PC cell lines compared with HPDE6-C7 cells (Fig. 1B). These data indicated that the expression of PPM1H was downregulated in PC cells.

Effect of TGF- $\beta 1$ and BMP2 on EMT and PPM1H expression in PC cells. TGF- $\beta 1$ and BMP2 were demonstrated to be involved in the process of EMT in tumor cells so as to increase their ability of invasion and metastasis. As showed by western blotting, after treatment with $10 \mathrm{ng} / \mathrm{ml}$ TGF- $\beta 1$ or $200 \mathrm{ng} / \mathrm{ml} \mathrm{BMP} 2$ for $72 \mathrm{~h}$, the expression of E-cadherin in BxPC-3 cells was decreased, and the expression of vimentin was increased, indicating EMT of BxPC-3 cells were induced. 
A
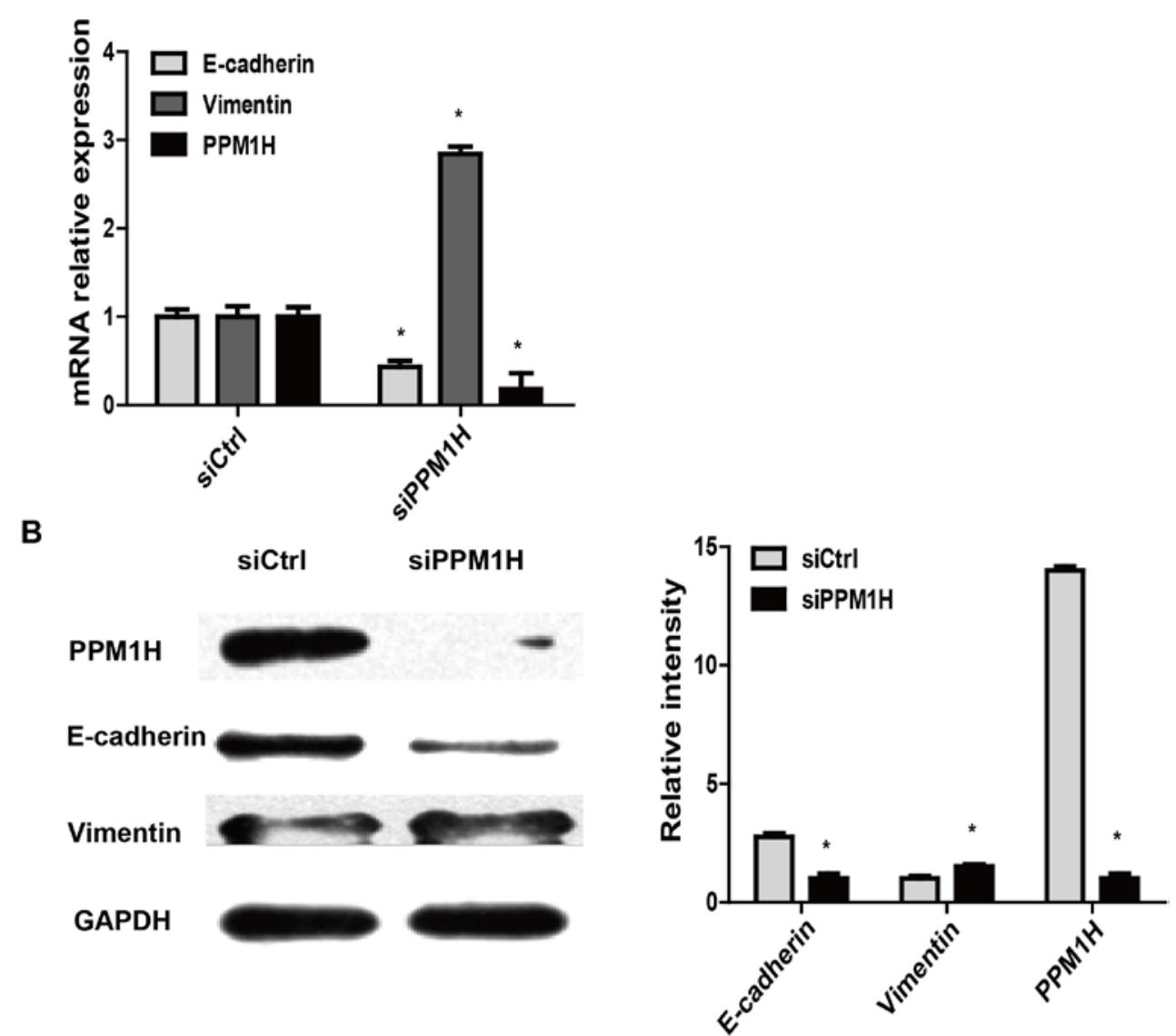

Figure 3. Silencing PPM1H induces EMT in BxPC-3 cells. BxPC-3 cells were transiently transfected with siPPM1H or siCtrl. After 72 h, RT-PCR (A) and western blotting (B) were performed to examine the expression of PPM1H, E-cadherin and vimentin at mRNA and protein levels, respectively. GAPDH was used as an internal control. ${ }^{*} \mathrm{P}<0.05$.

In addition, the expression of PPM1H was significantly reduced in TGF- $\beta 1$ or BMP2 treated BxPC- 3 cells $(\mathrm{P}<0.05$, Fig. 2). These data suggested that PPM1H may participate in the regulation of EMT.

PPMIH gene knockdown induces EMT in PC cells. To investigate whether PPM1H could induce EMT in PC cells, PPM1H specific siRNA were used to silence PPM1H expression. EMT-related markers E-cadherin and vimentin were detected by real-time PCR and western blotting, respectively, in PPM1H siRNA (si-PPM1H) transfected BxPC-3 cells. The data showed in BxPC-3 cells that downregulated E-cadherin and upregulated vimentin expression were induced by PPM1H gene silencing $(\mathrm{P}<0.05$, Fig. 3), indicating PPM1H gene silencing may cause EMT in PC cells.

PPM1H knockdown promotes invasion and migration of PC cells. Next, we used Transwell cell migration assay to examine the role of PPM1H in invasion and migration of PC cells. The cell migration rates were compared in PPM1H siRNA treated group and control group. The data showed that the cells penetrated the artificial basement membrane in siPPM1H group were two to three times more than in siCtrl group $(\mathrm{P}<0.05$, Fig. 4), implicating that PPM1H depletion resulted in increased invasion and migration of PC cells.
PPMIH knockdown promotes proliferation and inhibits apoptosis of PC cells. To further determine the role of PPM1H in PC cells, we assessed the effect of PPM1H depletion on cell proliferation and apoptosis. It was shown that silencing $\mathrm{PPM} 1 \mathrm{H}$ resulted in increased proliferation rate in BxPC-3 cells $(\mathrm{P}<0.05$, Fig. $5 \mathrm{~A})$. We also found that the apoptosis rate was reduced nearly $20 \%$ in siPPM1H group compared to siCtrl group $(\mathrm{P}<0.05$, Fig. 5B). These results demonstrated that PPM1H silencing could promote proliferation and inhibit apoptosis of PC cells.

PPM1H knockdown promotes Akt phosphorylation of PC cells. To explore the mechanisms involved in PPM1H function in PC cells, we tested Akt activity of BxPC-3 by western blotting. As shown in Fig. 6, silencing PPM1H can increase Akt phosphorylation. This result suggested that PPM1H may function through the Akt signaling pathway.

\section{Discussion}

The morbidity and mortality of pancreatic cancer have been gradually rising, while those of other common cancers have been declining (7). Although the detection and management of pancreatic cancer have achieved certain developments, only less than $5 \%$ of patients live 5 years after diagnosis $(6,7)$. Since 

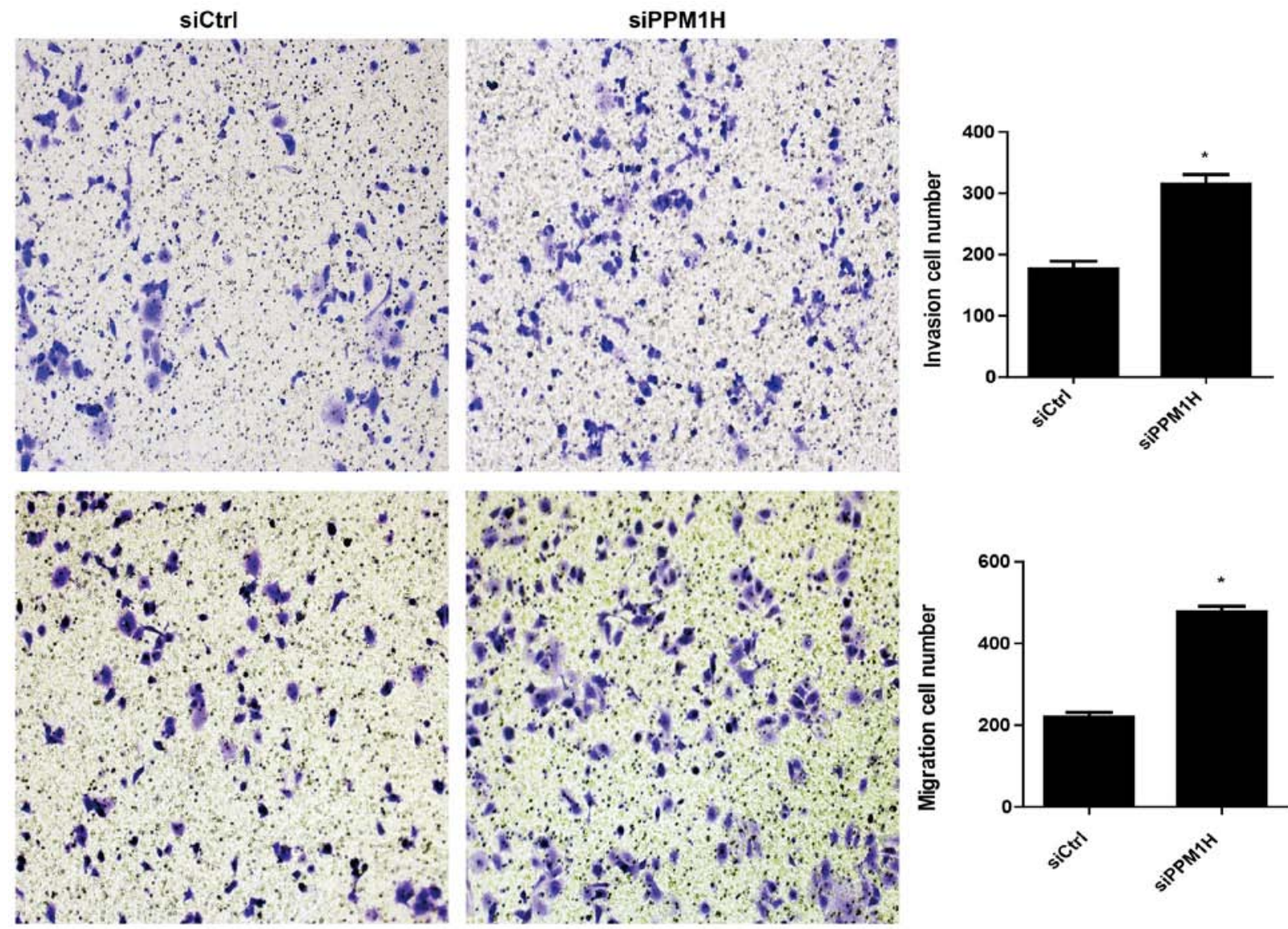

Figure 4. Silencing PPM1H promotes invasion and migration ability of BxPC-3 cells. BxPC-3 cells were transfected with siPPM1H or siCtrl. After $72 \mathrm{~h}$, cells $\left(8 \times 10^{4}\right)$ were loaded into the top chamber of 24 -well Transwell plates and incubated for another $24 \mathrm{~h}$. The migrated cells were stained with $0.1 \%$ crystal violet and the average number per field was quantified under high power (original magnification $\mathrm{x} 200$ ) of the phase contrast microscope. ${ }^{*} \mathrm{P}<0.05$.
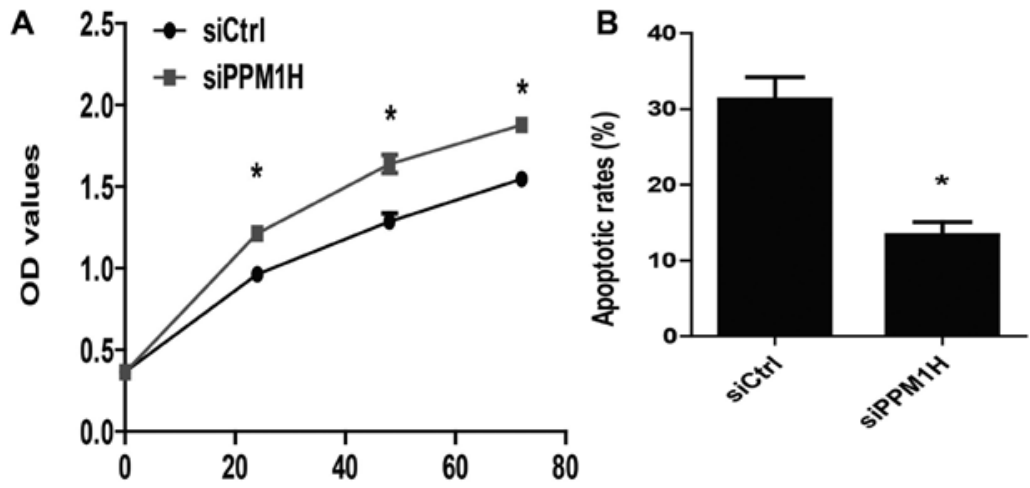

Figure 5. Effects of PPM1H silencing on cell proliferation and apoptosis of BxPC-3 cells. (A) Silencing PPM1H promoted cell growth as determined by CCK8 assay. Each bar represents the average \pm SD of three independent experiments. (B) Silencing PPM1H inhibited the apoptosis of BxPC-3 cells by flow cytometry. Each bar represents the average \pm SD of three independent experiments. ${ }^{*} \mathrm{P}<0.05$.

its malignant degree is high and the rate of resection is low, and pancreatic cancer responds poorly to most chemotherapeutic agents, it is urgent for us to understand the biological mechanisms that contribute to development and progression of pancreatic cancer.

EMT was initially considered to be an important feature of embryonic differentiation and morphology. And now, it has been demonstrated to be involved in the development of many diseases, such as inflammation, fibrosis and tumor (35). Accumulating evidence has indicated that EMT can promote an early stage tumor into aggressive malignant tumor by increasing the motility and invasiveness of the cells, this process was consistent with the acquisition of tumor stem cell phenotype (36-39). Some studies have shown that EMT can increase the invasive and anti-apoptosis capacity of cells, and may also affect its ability to resist chemotherapy. In recent years, EMT has been considered to play a critical role in the high drug-resistance and invasion of pancreatic cancer, therefore, the study of EMT in pancreatic cancer is helpful for the development of new drugs and new targets for molecular therapy. 

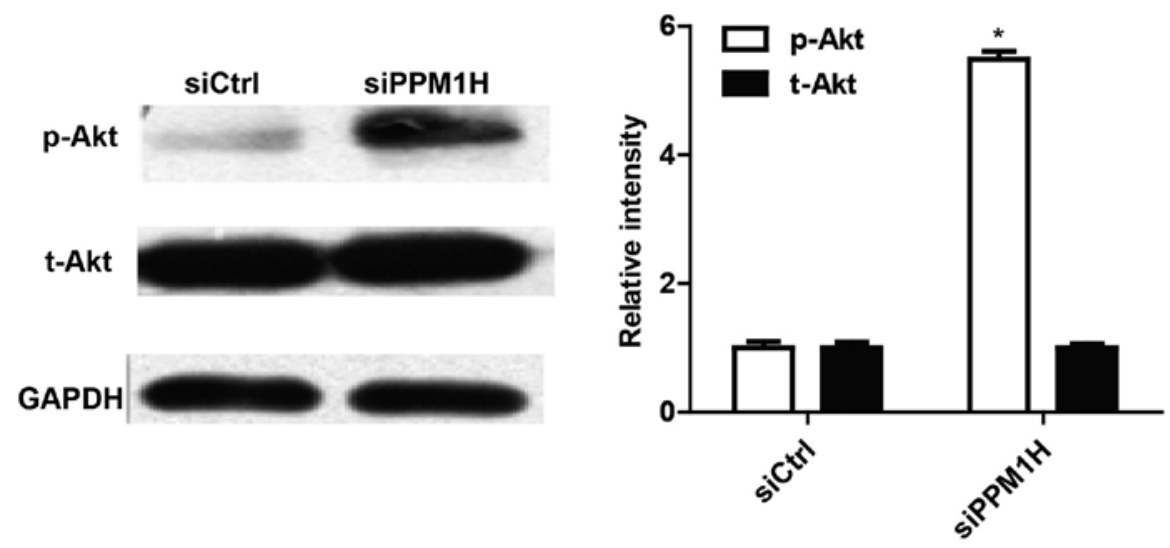

Figure 6. Silencing PPM1H can promote Akt phosphorylation..'P $<0.05$

Phosphorylation and dephosphorylation of proteins have important effect on the regulation of life activities of eukaryotic organisms, and the process of phosphorylation is co-regulated by protein kinase and protein phosphatase. Protein phosphatase is a kind of key enzyme that controls dephosphorylation of proteins. Its absence or dysfunction can lead to a variety of diseases. PPM1H (protein phosphatase, $\mathrm{Mg}^{2+} / \mathrm{Mn}^{2+}$ dependent $1 \mathrm{H}$ ) is a member of the PP2C family of Ser/ Thr protein phosphatases, which is not sensitive to Okada acid. Most members of the PP2C family have been shown to act as inhibitors of cell growth and cellular stress signaling. These members include PP2C $\alpha$, PP2C $\beta$, and the recently identified PP2Cs, ILKAP, and PHLPP; ILKAP negatively affects proliferation and malignant transformation, and PHLPP promotes apoptosis and inhibits tumor growth. Based on these observations, it is reasonable to assume that, in general, type $2 \mathrm{C}$ phosphatases act as tumor suppressor proteins. In addition to the PP2Cס (PPM1D/Wip1), which behaves as an oncogene (40-43).

At present, there are few studies on PPM1H in tumor, and the effect of PPM1H is controversial. As the result of this study shows that PPM1H was downregulated at both transcriptional and translational levels in five human pancreatic cancer cell lines compared with normal pancreatic ductal epithelial cell line $(\mathrm{P}<0.05)$, these results were different from the research of Sugiura et al in colon cancer cell lines (31). These results suggested that PPM1H plays a complex role in cancer and the effect of PPM1H may vary among cancers of different organs or tissues. Based on this result, we speculated that PPM1H may act as a tumor suppressor in pancreatic cancer.

Both TGF- $\beta 1$ and BMP2 can regulate EMT through Smad signaling pathway and non-Smad signaling pathway, the latter is considered to play a more important role in the process of inducing EMT (26-27,44-46). Our study demonstrated that both TGF- $\beta 1$ and BMP 2 can induce EMT in BxPC- 3 cells, interestingly the expression of PPM1H was significantly downregulated after induction of EMT. It suggests that PPM1H may participate in the regulation of EMT. To further confirm the role of PPM1H in EMT of pancreatic cancer cells, we chose BxPC-3 cell line for PPM1H silencing in which endogenous PPM1H expression was at relatively high level. We used interference RNA (RNAi) technique to induce PPM1H gene silencing, and qRT-PCR and western blotting were used to detect the expression of PPM1H and EMT related molecules. After silencing PPM1H, the expression of epithelial mesenchymal phenotype E-cadherin was downregulated, while the expression of mesenchymal phenotype vimentin was upregulated in $\mathrm{BxPC}-3$ cells $(\mathrm{P}<0.05)$. It was indicated that deletion of PPM1H gene can promote EMT independently in BxPC-3 cells. Then, we used Transwell cell invasion and migration assay to examine whether the invasion and metastasis capacity would be promoted when BxPC-3 cells were induced in EMT. The results showed that the invasion and metastasis of BxPC-3 cells were enhanced after silencing PPM1H $(\mathrm{P}<0.05)$, which illustrated that silencing PPM1H could enhance the invasion and metastasis of pancreatic cancer cells by promoting EMT.

The studies of Lee-Hoeflich et al have found that the loss of PPM1H gene can lead P27 suppressor gene to degrade so as to promote the proliferation of breast cancer cells (32). Hence, we speculated that PPM1H might suppress the proliferation of pancreatic cancer cells. We performed CCK8 assays to investigate the effect of PPM1H silencing on the proliferation of BxPC-3 cells. Our results showed that knockdown of PPM1H resulted in a more dramatic increase of the proliferation rate in BxPC-3 cells than that in control cells $(\mathrm{P}<0.05)$. PPM1H could suppress cell proliferation of BxPC-3 cells in vitro. In addition, we assessed that silencing PPM1H can inhibit the apoptosis of BxPC-3 cells by flow cytometry $(\mathrm{P}<0.05)$. Although we found that silencing PPM1H gene can promote proliferation and inhibits apoptosis of BxPC-3 cells, its specific mechanism still needs further exploration.

Since Smad4 is homozygously deleted in BxPC-3 cells (47), we suspected that PPM1H affect is through non-Smad pathway. In particular, it has been reported that mutation or deletion of Smad4 is found in approximately $50 \%$ of pancreatic tumors and is correlated with poor prognosis (48). Thus, it may be more important to investigate non-Smad pathways in detail in order to further understand invasion and metastasis of pancreatic cancer. In this study, we found that silencing PPM1H can increase Akt phosphorylation. The Akt signaling pathway is involved in many cellular processes during the occurrence and development of cancer, such as proliferation, apoptosis, invasion and metastasis $(49,50)$. Dephosphorylation of Akt can make it inactive, and thus inhibit the various biological activities of Akt. This 
result suggests that the PPM1H biological effects may be through the Akt signaling pathway.

Although we have demonstrated that silencing PPM1H can increase the invasion and metastasis of BxPC-3 cells, as well as promote its proliferation and inhibit apoptosis, we also need to explore the specific mechanisms of these effects. Whether silencing PPM1H can also promote BxPC-3 cells to acquire CSC characteristics so that it can induce chemotherapeutic resistance of BxPC-3 cells, and whether overexpression of PPM1H could reverse the above process is not known.

PPM1H presented low expression in pancreatic cancer cell lines, and silencing PPM1H can enhance the invasion and metastasis of BxPC-3 cells by mediating EMT. Silencing PPM1H also promotes proliferation and inhibits apoptosis of BxPC-3 cells. These effects may be produced by increasing AKT phosphorylation. This study suggests that PPM1H may be a novel tumor suppressor gene for pancreatic cancer. A better understanding of the function of PPM1H in pancreatic cancer is expected to provide new insight into the molecular targets of gene therapy for pancreatic cancer.

\section{References}

1. Siegel R, Naishadham D and Jemal A: Cancer statistics, 2012. CA Cancer J Clin 62: 10-29, 2012.

2. Siegel R, Naishadham D and Jemal A: Cancer statistics, 2013. CA Cancer J Clin 63: 11-30, 2013.

3. Stathis A and Moore MJ: Advanced pancreatic carcinoma: Current treatment and future challenges. Nat Rev Clin Oncol 7: 163-172, 2010.

4. Xu C, Li H, Su C and Li Z: Viral therapy for pancreatic cancer: Tackle the bad guys with poison. Cancer Lett 333: 1-8, 2013.

5. Hidalgo M: Pancreatic cancer. N Engl J Med 362: 1605-1617, 2010.

6. American Cancer Society: Cancer Facts \& Figures 2009. American Cancer Society, Atlanta, GA, pp18-19, 2009.

7. Vincent A, Herman J, Schulick R, Hruban RH and Goggins M: Pancreatic cancer. Lancet 378: 607-620, 2011.

8. Sarkar FH, Li Y, Wang Z and Kong D: Pancreatic cancer stem cells and EMT in drug resistance and metastasis. Minerva Chir 64: 489-500, 2009.

9. Li Y, Kong D, Ahmad A, Bao B and Sarkar FH: Pancreatic cancer stem cells: Emerging target for designing novel therapy. Cancer Lett 338: 94-100, 2013.

10. Tsuji T, Ibaragi S and Hu GF: Epithelial-mesenchymal transition and cell cooperativity in metastasis. Cancer Res 69: 7135-7139, 2009.

11. Arumugam T, Ramachandran V, Fournier KF, Wang H, Marquis L, Abbruzzese JL, Gallick GE, Logsdon CD, McConkey DJ and Choi W: Epithelial to mesenchymal transition contributes to drug resistance in pancreatic cancer. Cancer Res 69: 5820-5828, 2009.

12. Rasheed ZA, Yang J, Wang Q, Kowalski J, Freed I, Murter C, Hong SM, Koorstra JB, Rajeshkumar NV, He X, et al: Prognostic significance of tumorigenic cells with mesenchymal features in pancreatic adenocarcinoma. J Natl Cancer Inst 102: 340-351, 2010.

13. Ali S, Ahmad A, Banerjee S, Padhye S, Dominiak K, Schaffert JM, Wang Z, Philip PA and Sarkar FH: Gemcitabine sensitivity can be induced in pancreatic cancer cells through modulation of miR-200 and miR-21 expression by curcumin or its analogue CDF. Cancer Res 70: 3606-3617, 2010.

14. Singh A and Settleman J: EMT, cancer stem cells and drug resistance: An emerging axis of evil in the war on cancer. Oncogene 29: 4741-4751, 2010.

15. Polyak K and Weinberg RA: Transitions between epithelial and mesenchymal states: Acquisition of malignant and stem cell traits. Nat Rev Cancer 9: 265-273, 2009.

16. Iwatsuki M, Mimori K, Yokobori T, Ishi H, Beppu T, Nakamori S, Baba $\mathrm{H}$ and Mori M: Epithelial-mesenchymal transition in cancer development and its clinical significance. Cancer Sci 101: 293-299, 2010
17. Castellanos JA, Merchant NB and Nagathihalli NS: Emerging targets in pancreatic cancer: Epithelial-mesenchymal transition and cancer stem cells. Onco Targets Ther 6: 1261-1267, 2013.

18. Shin SJ, Kim KO, Kim MK, Lee KH, Hyun MS, Kim KJ, Choi JH and Song HS: Expression of E-cadherin and uPA and their association with the prognosis of pancreatic cancer. Jpn J Clin Oncol 35: 342-348, 2005.

19. Li Y, VandenBoom TG II, Kong D, Wang Z, Ali S, Philip PA and Sarkar FH: Up-regulation of miR-200 and let-7 by natural agents leads to the reversal of epithelial-to-mesenchymal transition in gemcitabine-resistant pancreatic cancer cells. Cancer Res 69: 6704-6712, 2009.

20. Nagaraj NS, Washington MK and Merchant NB: Combined blockade of Src kinase and epidermal growth factor receptor with gemcitabine overcomes STAT3-mediated resistance of inhibition of pancreatic tumor growth. Clin Cancer Res 17: 483-493, 2011.

21. Raida M, Clement JH, Leek RD, Ameri K, Bicknell R, Niederwieser D and Harris AL: Bone morphogenetic protein 2 (BMP-2) and induction of tumor angiogenesis. J Cancer Res Clin Oncol 131: 741-750, 2005.

22. Wakefield LM and Hill CS: Beyond TGF $\beta$ : Roles of other TGF $\beta$ superfamily members in cancer. Nat Rev Cancer 13: 328-341, 2013.

23. Carreira AC, Alves GG, Zambuzzi WF, Sogayar MC and Granjeiro JM: Bone morphogenetic proteins: Structure, biological function and therapeutic applications. Arch Biochem Biophys 561: 64-73, 2014.

24. Senturk S, Mumcuoglu M, Gursoy-Yuzugullu O, Cingoz B, Akcali KC and Ozturk M: Transforming growth factor-beta induces senescence in hepatocellular carcinoma cells and inhibits tumor growth. Hepatology 52: 966-974, 2010.

25. Ikushima $\mathrm{H}$ and Miyazono K: TGFbeta signalling: A complex web in cancer progression. Nat Rev Cancer 10: 415-424, 2010.

26. Kaminska B, Wesolowska A and Danilkiewicz M: TGF beta signalling and its role in tumour pathogenesis. Acta Biochim Pol 52: 329-337, 2005

27. Wharton K and Derynck R: TGFbeta family signaling: Novel insights in development and disease. Development 136: 3691-3697, 2009.

28. Chen X, Liao J, Lu Y, Duan X and Sun W: Activation of the PI3K/Akt pathway mediates bone morphogenetic protein 2 -induced invasion of pancreatic cancer cells Panc-1. Pathol Oncol Res 17: 257-261, 2011.

29. Kang MH, Oh SC, Lee HJ, Kang HN, Kim JL, Kim JS and Yoo YA: Metastatic function of BMP-2 in gastric cancer cells: The role of PI3K/AKT, MAPK, the NF- $x$ B pathway, and MMP-9 expression. Exp Cell Res 317: 1746-1762, 2011.

30. Cano CE, Motoo Y and Iovanna JL: Epithelial-to-mesenchymal transition in pancreatic adenocarcinoma. Sci World $\mathbf{J} 10$ : 1947-1957, 2010.

31. Sugiura T, Noguchi Y, Sakurai K and Hattori C: Protein phosphatase $1 \mathrm{H}$, overexpressed in colon adenocarcinoma, is associated with CSE1L. Cancer Biol Ther 7: 285-292, 2008.

32. Lee-Hoeflich ST, Pham TQ, Dowbenko D, Munroe X, Lee J, Li L, Zhou W, Haverty PM, Pujara K, Stinson J, et al: PPM1H is a 27 phosphatase implicated in trastuzumab resistance. Cancer Discov 1: 326-337, 2011.

33. Aceto $\mathrm{N}$ and Bentires-Alj M: On the road to combinations of targeted therapies: PPM1H phosphatase as a suppressor of trastuzumab resistance. Cancer Discov 1: 285-286, 2011.

34. Shen T, Sun C, Zhang Z, Xu N, Duan X, Feng XH and Lin X: Specific control of BMP signaling and mesenchymal differentiation by cytoplasmic phosphatase PPM1H. Cell Res 24: 727-741, 2014.

35. Thiery JP, Acloque H, Huang RY and Nieto MA: Epithelialmesenchymal transitions in development and disease. Cell 139: 871-890, 2009.

36. Christiansen JJ and Rajasekaran AK: Reassessing epithelial to mesenchymal transition as a prerequisite for carcinoma invasion and metastasis. Cancer Res 66: 8319-8326, 2006.

37. Mani SA, Guo W, Liao M-J, Eaton EN, Ayyanan A, Zhou AY, Brooks M, Reinhard F, Zhang CC, Shipitsin M, et al: The epithelial-mesenchymal transition generates cells with properties of stem cells. Cell 133: 704-715, 2008.

38. Floor S, van Staveren WC, Larsimont D, Dumont JE and Maenhaut C: Cancer cells in epithelial-to-mesenchymal transition and tumor-propagating-cancer stem cells: Distinct, overlapping or same populations. Oncogene 30: 4609-4621, 2011. 
39. Santisteban M, Reiman JM, Asiedu MK, Behrens MD, Nassar A, Kalli KR, Haluska P, Ingle JN, Hartmann LC, Manjili MH, et al: Immune-induced epithelial to mesenchymal transition in vivo generates breast cancer stem cells. Cancer Res 69: 2887-2895, 2009.

40. Shreeram S and Bulavin DV: PPM1H - new kid on the block. Cancer Biol Ther 7: 293-294, 2008.

41. Leung-Hagesteijn C, Mahendra A, Naruszewicz I and Hannigan GE: Modulation of integrin signal transduction by ILKAP, a protein phosphatase $2 \mathrm{C}$ associating with the integrinlinked kinase, ILK1. EMBO J 20: 2160-2170, 2001.

42. Gao T, Furnari F and Newton AC: PHLPP: A phosphatase that directly dephosphorylates Akt, promotes apoptosis, and suppresses tumor growth. Mol Cell 18: 13-24, 2005.

43. Shreeram S, Demidov ON, Hee WK, Yamaguchi H, Onishi N, Kek C, Timofeev ON, Dudgeon C, Fornace AJ, Anderson CW, et al: Wip1 phosphatase modulates ATM-dependent signaling pathways. Mol Cell 23: 757-764, 2006.

44. Derynck R and Zhang YE: Smad-dependent and Smadindependent pathways in TGF-beta family signalling. Nature 425: 577-584, 2003.
45. Moustakas A and Heldin CH: Non-Smad TGF-beta signals. J Cell Sci 118: 3573-3584, 2005.

46. Gordon KJ, Kirkbride KC, How T and Blobe GC: Bone morphogenetic proteins induce pancreatic cancer cell invasiveness through a Smad1-dependent mechanism that involves matrix metalloproteinase-2. Carcinogenesis 30: 238-248, 2009.

47. Deer EL, González-Hernández J, Coursen JD, Shea JE, Ngatia J, Scaife CL, Firpo MA and Mulvihill SJ: Phenotype and genotype of pancreatic cancer cell lines. Pancreas 39: 425-435, 2010.

48. Wilentz RE, Iacobuzio-Donahue CA, Argani P, McCarthy DM, Parsons JL, Yeo CJ, Kern SE and Hruban RH: Loss of expression of Dpc4 in pancreatic intraepithelial neoplasia: Evidence that DPC4 inactivation occurs late in neoplastic progression. Cancer Res 60: 2002-2006, 2000.

49. Chang F, Lee JT, Navolanic PM, Steelman LS, Shelton JG, Blalock WL, Franklin RA and McCubrey JA: Involvement of PI3K/Akt pathway in cell cycle progression, apoptosis, and neoplastic transformation: A target for cancer chemotherapy. Leukemia 17: 590-603, 2003.

50. Altomare DA and Testa JR: Perturbations of the AKT signaling pathway in human cancer. Oncogene 24: 7455-7464, 2005. 